\title{
Comparative Study on Animation Creation Styles under Chinese and Western Aesthetic Thoughts
}

\author{
Xi Niu \\ Zhengzhou Institute of Aeronautical Industry Management \\ Zhengzhou, China
}

\begin{abstract}
Due to the difference in the aspects of historical conditions, cultural traditions and aesthetic psychology, Chinese and Western aesthetics have a great difference, forming two aesthetic thoughts systems, namely, Eastern and Western. This paper conducted contrastive analysis and study on animation creation style influenced by Chinese and Western aesthetic thoughts from the aspects such as role model, scene, movement display, lens language, music and dubbing.
\end{abstract}

Keywords-Chinese aesthetic thoughts; western aesthetic thoughts; animation creation style

\section{INTRODUCTION}

Chinese and Western aesthetic thoughts have basically the same nature, but Chinese and Western aesthetic thoughts are bonded by general rule of different cultural attributes which are extended from different regions, different countries and different nationalities, resulting in great difference of Chinese and Western aesthetics in representation. The formed eastern and western aesthetic thoughts systems today still have different entry points and artistic creation contents in the aspects of history, culture and aesthetic. [1] The difference of these contents in esthetic thoughts deeply influences the artistic style of Chinese and Western animation creation.

\section{DifFERENCE OF CHINESE AND WESTERN AESTHETIC THOUGHTS}

\section{A. Chinese Aesthetic Thoughts}

Ancient Chinese aesthetic thoughts have both similarities and differences. For example, Confucius said, "Where natural simplicity (zhi) exceeds cultural refinement (wen), you have the rustic; where cultural refinement exceeds natural simplicity, you have the ostentatious. It is only when simplicity and refinement are blended harmoniously and complement each other that you have a gentleman. "Where, "Zhi" refers to human's morality, while "wen" refers to

Fund projects:

2015 general project on humanistic and social science research by the Education Department Henan Province, No. 2015-QN-406

2015 research project of Henan Federation of Social Science Circles and Henan Federation of Economic Organizations, No. SKL-2015-80. Optional 2014 youth research fund project of Zhengzhou Institute of Aeronautical Industry Management, No. 2014142002

2015 educational scientific research fund project of Zhengzhou Institute of Aeronautical Industry Management, No. 40 human's cultural refinement. That is to say, it is only when human's moral goodness and exterior refinement are properly blended, that we have the truly wise and good man. Confucius further puts forward the aesthetical standard of "Happy but not too much, grief without injury". It means that the emotion contained in art shall be a moderate emotion conforming to rational norms. In fact, the aesthetical standard put forward by Confucius reflects the thought of "Harmony". Therefore, Confucianism believes that morals, emotion and harmony can be regarded as beauty in nature. Lao $\mathrm{Zi}$ said, "It is because everyone under Heaven recognizes beauty as beauty, that the idea of ugliness exists. And equally if everyone recognized virtue as virtue, this would merely create fresh conceptions of wickedness."Lao $\mathrm{Zi}$ believes that beauty and ugliness, and virtue and wickedness are mutually contradictory and mutually unified. [2] Therefore, Lao $\mathrm{Zi}$ generally adopts negative attitude towards formal beauty in real society in his aesthetic thoughts. As another example, "Calm and repose are what he prizes; victory (by force of arms) is to him undesirable", all express a special aesthetic standard. Therefore, Taoists discuss the beauty without actions, with sounds, without shapes, without words and without taste. Taoists regard nothingness, ingenuity, tasteless, tenderness, naturalness, vitality and suitability as beauty, while Buddhists regard Nirvana, Quietus, death and the symbol of Nirvana-completeness and brightness as beauty, reflecting the diversity of ancient Chinese aesthetic theory. ${ }^{[3]}$ The aesthetic view point of Buddhism believes that "Form is emptiness"; human's attachment and obsession to beautiful things of physical world is the source of infinite pain of life, and that the beauty of physical world is illusory and untrue. Therefore, Buddhism emphasizes to break away from craving for the beauty of object and form. ${ }^{[5]}$ On the one hand, Buddhism objects to worldly beauty, on the other hand, the thinking method of "Madhyamika" makes Buddhism affirm the beauty of Nirvana. Ancient Chinese aesthetic thoughts have unique national personality, and make independent, selfsufficient and in-depth explanation for core problems of aesthetics, which not only influences human's mind and body, but also influences the aspects of ancient construction, decoration and interior space design.

Chinese design aesthetics is a constituent part of the history of Chinese esthetics, demonstrating corresponding aesthetic characteristics. ${ }^{[6]}$ Under the influence of rites \& music aesthetic thoughts, design aesthetics and artistic design 
spiral centering on the change of content and form. Under the influence of aesthetic thoughts of Lao $\mathrm{Zi}$ and $\mathrm{Zhuang} \mathrm{Zi}$, design aesthetics boldly progresses in the aspects of skill, imagination and freedom, and reflects the pattern and style different from those of Confucianism aesthetics thoughts. Meanwhile, design science is affected by "Jingchu culture". Design aesthetics has unique development in folk art modeling. These three design aesthetics jointly form the pattern of design science. Moreover, it is also influenced by the Book of Changes. The representative of Confucianism aesthetics is the thoughts of Confucius and Mencius ${ }^{[7]}$. The aesthetics of Confucius and Mencius reflects the orthodox dominant aesthetic consciousness. Under the influence of this aesthetic inclination and aesthetic idea, design aesthetics shows the aesthetic consciousness and reflects the aesthetic concept of Confucianism.

\section{B. Western Aesthetic Thoughts}

With ancient Greek entering the heyday of slave society, ancient Greek conducted philosophical \& critical reflection and thinking for aesthetics and art, and the earliest aesthetic thoughts of Greece was generated and formed. It changes with the development of times. The Pythagorean School in the 6th century BC holds that order of number, proportion and scale not only constitute the cosmic inventory, but also constitute the harmony of universe. Beauty is generated from harmony. According to this viewpoint, they further put forward aesthetic viewpoints such as "golden section" and "variety in unity". Herakleitos carries on Pythagoras's viewpoint on harmony. However, he holds that harmony is not caused by "uniting things of the same kind", instead, "the most beautiful harmony" is "combined by mutually exclusive things"; harmony is generated from conflict. Plato holds that the inner spiritual harmony of things is the depth connotation of beauty. However, Aristotle objects to this viewpoint and holds that beauty is related to size and order. Plotinus deepens the thought of Plato, guides aesthetics to theology idealism, and starts the aesthetic thoughts of the Middle Ages. The aesthetic thoughts in the Middle Ages are complex and conflict. It is an appendage to theology, at the same time, it has things opposing to theology. The aesthetic thoughts in renaissance are bred from the embryo of aesthetic thoughts in the Middle Ages. Western aesthetic thoughts constantly change with the development of times. The westerners are always indulged in the understanding for the essence of things. After continuous exploration and study, they put forward the law of "formal beauty".

The source of western design aesthetics is Greece. Greek aesthetics has a full set of ideological system. Plato and Aristotle epitomized the Greek aesthetics. Western design art is influenced by the aesthetics of Plato and Aristotle. Design aesthetics and artistic design develop around concept and art form. Concept is an unspecific and infinite strength. It gives people the space of imagination. Concept and form are incompatible movement forming reality and imagination, as well as reality and ideal. ${ }^{[8]}$ In design modeling, the art, sculpture and building in religious theme reflect the process of spiral movement in this aspect.

\section{COMPARISON OF ANIMATION CREATION STYLES UNDER THE INFLUENCE OF CHINESE AND WESTERN AESTHETICS}

In the development process of animation art creation, due to the influence of their own histories and cultures and the difference of Chinese and Western aesthetic thoughts, eastern and western countries have formed different animation creation styles. Taking the most representative America as an example, this paper compares the similarities and differences of animation creation styles of America and China.

\section{A. Role Modeling Design}

In early stage, American animation pursued exaggerated modeling effect. Substantial exaggeration of role model became an important element in comedy representation. The role model in American animation has a distinct difference in good and evil performance. Personal character agrees with the modeling. Taking the roles in Snow White as an example, the model of the heroine Snow White has a smooth figure, mellow and full face, bright eyes, and small and exquisite features which fully reflect her gentle personality. However, the model of the Queen (villain) has a stiff figure, compact features and rising eyes and eyebrows which reflect her malicious personality. It can be seen that American animation accurately grasps the role model and personality. In addition, American animation also has some animal characters as supporting actors which add humorous elements and comic effects to films ${ }^{[4]}$.

Early Chinese animation characters have distinct national features in design in modeling, color, clothing and prop, etc., and most of them are characters. The style of role model will agree with overall style of film. The figure is smooth, mellow and full; the color is fresh and elegant; and there are both true-life and exaggerated modelings. Taking Havoc in Heaven as an example, the character design uses facial makeup of Chinese operas for reference. The modeling of the hero Sun Wukong combines the image features of monkey and human. The outline shape of features is embodied by simple facial lines; the embellishing effect is achieved while shaping the body. In addition, the role modeling of Chinese animation pays attention to the combination with traditional culture and art. The images of some gods and ghosts have unique Eastern culture color.

\section{B. Scene Design}

The scene design of American animation is much more detailed and realistic than character design, and belongs to the realistic style. The scene design of American animation pays attention to composition, perspective, proportional relation and details. Plants and trees, mountains and rivers, plains and valleys, sunrise and sunset, etc, in the scene give the feeling of reality from color and texture. In addition to modeling exquisite style, the scene design of American animation also pays attention to creating atmosphere and the momentum of scene. In animation scene, the scene uses big contrast colors to achieve the scene effect of vivid color, rich levels and full of vigor and vitality. [4] Moreover, the 
expression techniques of Western oil paintings are used for reference. The utilization of perspective and light \& shadow effect in animation scene is an important means to express scene and set off atmosphere by contrast. In this way, the $3 \mathrm{D}$ effect of scene is increased; the sense of level and the sense of space in scene environment are expanded; infinite wide visual perception is displayed in limited space.

Although Chinese animation scene does not have the spectacular scene as that of American animation, it has unique scene design style. The theme of early Chinese animation mainly involves in ancient myths and folklores, resulting in the diversity of animation scene design style in this period. Early Chinese animation is influenced by traditional culture and art, such as folk art forms including freehand brushwork in traditional Chinese painting, facial makeup in Beijing opera, shadow play and paper-cut, and gives people diversified visual perception in role modeling and scene design. Compared with spectacular scene of American animation, Chinese animation pays more attention to creating details of scene and design style with fantastic color, and the used color is also brighter.

\section{Motion Display}

American animation has typical features in the aspect of action design, and pays special attention to the body motion display of character, as well as the coherence and elasticity of action, thus vitalizing the lifeless animation character. Moreover, exaggerated action design also adds quite a few humor colors and comedy effects to films. [9] With the improvement of technology, American animation gradually achieves very meticulous and precise presentation of complex body action, exaggerative facial expression and subtle eye expression of character, realizing the perfect combination of reality and imagination.

The movement display of character in Chinese animation is soft. Since the style of role modeling is diversified, the design of movement display is difficult. On the whole, the action coherence and elasticity of early animation characters are good. Early animation pays attention to the depiction of facial expression and eye expression, and has a little bit exaggerated effect. But the expression of scene is weak. Contemporary Chinese animation pays more attention to the combination of role action and scene animation. In addition, the animation production of special effects of details such as cloud mist and water mist also has good treatment effect.

\section{Lens Language}

Lens movement in animation is different from camera movement in film. Animation needs to display the 3D sense of space in 2D scene. In the phase of Snow White, American animation uses layering to display the vertical feeling of space. With the development of technology, this method becomes mature and vivid. Multiple-layer movement in moving lenses can be seen everywhere. [9] Contemporary American animation pays more attention to the movement of lens and the watching perspective. The fluency of lens movement is stronger. Lens movement, such as zoom in, zoom out, wave, move and follow, is more incisively and vividly displayed in animation.
Early Chinese animation absorbs and uses traditional Chinese art form for reference, and mostly selects paper-cut and shadow puppet, etc. as the expression pattern of animation, thus it is very difficult to present the lens movement of film. Therefore, lens movement of early Chinese animation mostly adopts the method of translation, meanwhile, the utilization of dolly shot will also be added to make up the incoherent action of character and the stiff scene. In the aspect of lens switching, the animation in this phase will increase the sense of rhythm utilizing editing skills according to the development of film plot.

\section{E. Music and Dubbing}

Early American animation makes a good combination of sound and scene, pays attention to matching the rhythm of music with the rhythmical point of action, and creates comedy effect. With the improvement of audience's appreciation level, American animation pays more attention to the expressive force of music and song so as to achieve the objective of guiding the audience to the situation and setting off the atmosphere by contrast. Chinese animation also has special music style. Early Chinese animation has national features and absorbs the art forms such as Chinese opera and shadow puppet. Therefore, the creation of music also reflects full-bodied folk characteristics.

\section{CONCLUSION}

Chinese aesthetics pursues the harmony and unity of nature, human and society, while Western aesthetic thoughts pursue the harmony and unity of art form. These two thoughts are fully reflected in animation creation style. From the angle of aesthetic style, the East pays attention to decorous and deep, while the West emphasizes humorous and relax; the East mainly makes meticulous description from microcosmic angle, while the West mainly makes appropriate exaggeration from macroscopic perspective. To sum up, the East lays particular stress on meticulous and graceful, while the West emphasizes noble and high. ${ }^{[10]}$ The comparison of animation creation styles influenced by Chinese and Western aesthetic thoughts is not to differentiate the superiority of one over another, but to discuss the depth connotation of Chinese and Western culture and the development law of art, and urge us to see the past and the future, learn widely from others' strong points to offset one's weakness, and create better animation works.

\section{REFERENCES}

[1] Zhang Jie. Structure of Arnheim aesthetic thoughts and schema analysis of pedigree $[\mathrm{J}]$. Art of Design (Journal of Shandong University of Art \& Design). 2014(05)

[2] Fan Meijun. Contemporary Interpretation of Traditional Chinese Aesthetics [M]. Peking University Press, 2006

[3] Gu Zuzhao, Guo Shuyun. Attemption on Integrating Chinese and Western Literature and Art Theories [M]. People's Literature Publishing House, 2005

[4] Wang Yuechuan. Art Ontology [M]. China Social Sciences Publishing House, 2005

[5] Liu Fang. Historical Evolution and Modern Transformation of Chinese Aesthetics [M]. Bashu Publishing House, 2005 
[6] Lu Xiaohui. Study on Genetics of Chinese Aesthetic Psychology [M]. China Social Sciences Publishing House, 2003.

[7] Liu Fang. Fundamental Spirit of Chinese Aesthetics and Its Modern Significance [M]. Bashu Publishing House, 2003

[8] Wang Xindong, Wang Wei. Similarities of Chinese and Western aesthetic category [J]. Journal of Southeast University (Philosophy and Social Science). 2012(03)

[9] Li Xingchen. Course on History of the Western Aesthetics [M]. Peking University Press, 2005.

[10] Deng Xiaomang. Three Topics of Chinese and Western Aesthetics Comparison [J]. Journal of Huazhong University of Science and Technology (Social Science Edition). 2012(01) 